\title{
Assessment and Comparison of Various MCDM Approaches in the Selection of Manufacturing Process
}

\author{
Atef M. Ghaleb $\mathbb{D}^{1}{ }^{1}$ Husam Kaid $\left(\mathbb{D},{ }^{1}\right.$ Ali Alsamhan, ${ }^{1}$ Syed Hammad Mian,,3 \\ and Lotfi Hidri (i) \\ ${ }^{1}$ Industrial Engineering Department, College of Engineering, King Saud University, P. O. Box 800, Riyadh 11421, Saudi Arabia \\ ${ }^{2}$ Advanced Manufacturing Institute, College of Engineering, King Saud University, P. O. Box 800, Riyadh 11421, Saudi Arabia \\ ${ }^{3}$ Raytheon Chair for Systems Engineering (RCSE Chair), King Saud University, P. O. Box 800, Riyadh 11421, Saudi Arabia
}

Correspondence should be addressed to Atef M. Ghaleb; amag16@gmail.com and Husam Kaid; yemenhussam@yahoo.com

Received 30 October 2019; Revised 18 February 2020; Accepted 14 March 2020; Published 9 April 2020

Academic Editor: Gianluca Percoco

Copyright (c) 2020 Atef M. Ghaleb et al. This is an open access article distributed under the Creative Commons Attribution License, which permits unrestricted use, distribution, and reproduction in any medium, provided the original work is properly cited.

The selection of manufacturing processes for a given application is a complex problem of multicriteria decision-making although there have been several different approaches that can be utilized to select a suitable alternative. However, identifying appropriate multicriteria decision-making approach from the list of available methods for a given application is a difficult task. This work suggests a methodology to assess different selection approaches, which are the technique for order of preference by similarity to ideal solution (TOPSIS), analytic hierarchy process (AHP), and VIKOR: stepwise procedure. This valuation was done depending on the following factors: number of alternative processes and criteria, agility through the process of decision-making, computational complexity, adequacy in supporting a group decision, and addition or removal of a criterion. A case study in this study was presented to analyse the evaluation methodology. The criteria used to evaluate and identify the best manufacturing process were categorized into productivity, accuracy, complexity, flexibility, material utilization, quality, and operation cost. Five manufacturing processes were considered, including gravity die casting, investment casting, pressure die casting, sand casting, and additive manufacturing. The results showed that each approach was suitable for the problems of manufacturing process selection, in particular toward the support of group decision-making and uncertainty modelling. Manufacturing processes were ranked based on their respective weights for AHP, TOPSIS, and VIKOR, and sand casting is the best. In terms of computational complexity, the VIKOR method performed better than TOPSIS and AHP. Moreover, the VIKOR and TOPSIS methods were better convenient to the selection of manufacturing processes for agility during the process of decision-making, the number of alternative processes and criteria, adequacy in supporting a group decision, and addition or removal of a criterion.

\section{Introduction}

The competitive market and precise and variable customer demands have given rise to a large number of manufacturing processes and techniques. As a result, a number of manufacturing alternatives are available for a given production application or a product. In fact, the choice of a manufacturing process for any product is a challenging issue [1]. It is because various manufacturing processes differ in their productivity and performance as well as economics. The preference of the manufacturing process for a given task is indeed complex due to several reasons. The intricate correlation between distinctiveness of manufacturing methods and selection rule causes the selection procedure a cumbersome and time-consuming task. The complication is further aggravated due to unequal importance assigned to multiple criteria in decision-making. Therefore, it is crucial to employ an effective and systematic approach to the selection of a manufacturing process for a given problem. For instance, Ullman, [2] emphasized the significance of rational approach in the process selection problem as well as the requirement of identifying the attributes that might affect the performance of the fabrication process for the specific component. 
The selection of appropriate process from the group of contrasting and diverse manufacturing processes can be accomplished through the implementation of multicriteria decision-making (MCDM) techniques. The MCDM is a very appropriate technique for analysing complex actual problems because of its ability to use certain criteria to assess different alternatives [3]. MCDM techniques are used to breakdown complex problems to minor parts [4], consequently that after performing the analyses, all parts will be placed together providing a complete image of the problem. The process of decision-making needs the previous definition and fulfilment of specific factors, particularly when need to solving the problems in the more complex zones [5] Also, in the science, the theory of MCDM takes a special and important place [6]. The application of multicriteria decision-making (MCDM) techniques assistances the decisionmaker to take into their consideration diverse criteria or goals in order to arrive a compromise between all potentially incompatible parameters $[7,8]$; consequently, decisionmaker has to take into consideration and evaluate quantitative and qualitative factors [9]. The MCDM approach may consider both subjective and quantitative attributes (and criteria). For different manufacturing process selection problems, a large number of criteria can be analysed. Therefore, it is critical to consider the following two factors in the decision-making problem when several alternatives are accessible. Foremost, it includes the choice regarding the various criteria affecting the given problem (e.g., manufacturing processes). The second factor involves the adoption of a most suitable MCDM approach for the problem at hand. It is a known fact that different MCDM methods possess variable performance and characteristics. Hence, it is not straightforward to determine and select one particular approach from the available MCDM methods. Most often, a comparative evaluation of different MCDM techniques becomes mandatory in order to improve selection efficiency and effectiveness.

It is obvious from the literature review that earlier research studies have concentrated on MCDM approaches, for example, fuzzy TOPSIS and fuzzy AHP for evaluation of supplier [3,10-12] and there is a lack of studies related to manufacturing process selection. Each technique has analysis models, information requirements, underlying assumptions, and decisions. This means that it is necessary to choose the most appropriate techniques to solve the manufacturing process selection problem being studied; otherwise, if an inappropriate technique is chosen, we arrive at misleading solutions. Thus, choosing the appropriate technique to solve the manufacturing process selection problem is in itself the most important question that must be considered. Therefore, it is necessary to do a comparative assessment of various approaches with regard to manufacturing process selection. To overcome this gap, this work is an extension of $[10,12]$ and introduces a methodology for the comparative analysis of MCDM methods, particularly related to manufacturing process selection. Moreover, the proposed approach aims at assessing MCDM methods based on these aspects: agility through the process of decision-making, computational complexity, number of alternative processes and criteria, adequacy in supporting a group decision, and addition or removal of a criterion. The different approaches that have been investigated included the AHP, TOPSIS, and VIKOR: stepwise procedure.

Other sections of this paper are arranged as follows: Section 2 describes a literature review pertaining to the selection criteria and approaches employed in manufacturing process preference. The subsequent section details the methodology adopted in this paper as well as some fundamental ideas connected to TOPSIS, AHP, and VIKOR methods. Section 4 shows the results of the implementation of the suggested approaches to a real case study. Section 5 carries out a comparative analysis of different MCDM approaches. Finally, in Section 6, final remarks and future directions are provided.

\section{Literature Review}

Multicriteria decision-making (MCDM) started in the 1970 s and was considered an interesting area for many researchers. From the beginning until now, more than 70 multicriteria decision-making techniques have been discovered [13], where the MCDM can be divided into two different classifications: multiobjective decision-making (MODM) and multiattribute decision-making (MADM). The multiobjective decision-making (MODM) aims to design alternatives which optimize the multiple objectives of decision maker [14]. The selections are generally very large or infinite, and the best selection will be which satisfies priorities and constraints of decision maker. Moreover, the multiattribute decision-making (MADM) involves the selection of a specific alternative from several alternatives that were previously determined based on features, so that this alternative is known as the best alternative [15]. The MADM is generally used to the solution of problems that have a limited number of alternatives. Among the techniques that have been developed for MCDM, each technique has analysis models, information requirements, underlying assumptions, and decisions [16]. This means that it is necessary to choose the most appropriate techniques to solve the problem being studied; otherwise, if an inappropriate technique is chosen, we arrive at misleading solutions. Therefore, inappropriate decisions will lead to very large losses. Therefore, choosing the appropriate technique to solve the problem is in itself the most important question that must be considered a lot before the selection is made, given the large warehouse of the MCDM techniques.

\subsection{Criteria and MCDM Approaches in the Selection Process.} Recent studies have concentrated on MCDM approaches, for example, fuzzy TOPSIS and fuzzy AHP for evaluation of supplier [3, 10-12]; fuzzy rule-based system (FRBS), fuzzy multicriteria decision-making (MCDM), stochastic MCDM, mathematical modelling, information theory, and heuristic approaches for evaluation of risks and failures of public transport systems [17], AHP for evaluation of waste treatment, supplier details, waste management cost, and waste handling procedure [18]; fuzzy AHP, quality function 
deployment (QFD) for evaluation of quality, cost, delivery time, and supplier standing [19]; multiattribute ideal-real comparative analysis (MAIRCA), best-worst method (BWM) for evaluation of flexibility, costs and price, profile of supplier, quality, and delivery [20]; fuzzy TOPSIS for evaluation of flexibility, delivery, reputation, quality, technology, and affairs of environment [21]; ANN and AHP for evaluation of service, cost, risk, delivery, and quality [22]; TOPSIS for evaluation of cost of purchasing, quality of product, stability of financial, delivery performance, facility and building, and personnel [23]; fuzzy TOPSIS and fuzzy AHP for evaluation of delivery, cost, service, relationship, and flexibility [24]; DEA for evaluation of price of purchasing, response time, quality, date of expiration, and reliability in delivery [25]; Z-TOPSIS, principal component analysis (PCA), and mixed integer linear programming for evaluation of quality, cost, delivery, profile of supplier, and services [26]; AHP for evaluation of cost, quality, regulatory compliance, reliability of service, management of risk, green purchasing, and profile of supplier [27]; fuzzy evaluation with MATLAB for environmental, social, and economic evaluation [28]; fuzzy VIKOR and artificial neural network for evaluation of quality, price, timely delivery, transporting and packaging quality, terms of payment, and the background of supplier [29]; Preference Ranking Organization METHod for Enrichment of Evaluations (PROMETHEE) $\Pi$ and TOPSIS for evaluation of on-time delivery, quality, reliance, flexibility, reputation, status financial status, previous cooperation experience, price, amount of material can be provided, and duration of delivery time [30]; and multichoice goal programming (MCGP) and fuzzy TOPSIS for evaluation of capacity of supply, capacity of production, time of response, technology of production, warranty, price, procedural compliance, transaction of purchase, quality, communication system, completed shipping document, ontime delivery, financial position, reputation, location, organization, and management [31].

\subsection{Application of MCDM Approaches in Manufacturing} Processes Selection. There have been many studies that have concentrated on the selection of manufacturing processes. For instance, a system known as MAPS-1 was introduced by Dargie et al. [32] to select appropriate materials and processes from several alternatives. It was a computer-aided design-based system for determining the suitable combination of manufacturing processes and materials depending on the part being processed. The application of this system was further extended by Shea et al. [33] through a procedure known as CAMPS (computer-aided material and process selection). The primary objective behind the establishment of CAMPS was the selection of appropriate manufacturing methods depending on the application requirement such as sheet-metal processing, machining, and casting. Similarly, an approach known as computer-oriented material, selection system of apparatus, and processes was adopted by Chan et al. [34]. This selection technique focused on choosing the manufacturing processes based on the available shop floor resources. An expert system named as Expert
Processing Sequence Selector was introduced by Farris and Knight [35] to identify the best operation sequence. The system considered geometrical and material constraints of design as input data. A number of processing orders and their ranking were suggested depending on the material compatibility and difficulty level of the manufacturing process. Yu et al. [36] proposed an expert system addressing the selection of net-shape manufacturing processes. The information regarding shape, production volume, and material was considered simultaneously as the basis in the selection of suitable process. The decision procedure pertaining to selection in manufacturing can be divided into preselection and final selection stages [37]. The preselection considers material selection, shape complexity, precision, and finish required, alternative process routes as well as cost related to each combination. The final stage involves the study of the most favorable processes in detail, depending on its availability, in-house experience, and environmental and safety issues. Certainly, the material and manufacturing process selection is an MCDM problem. These decisions are taken during initial design stages incorporating uncertainty elements, various factors, and their relationships. To address this aspect, Giachetti [38] introduced a material and manufacturing process selection system and named it as MAMPS. Based on the designer preference as well as other decision factors, an integrated system was established which stored information regarding various options and made decisions using possibility theory. Moreover, a material and process selection tool known as Manufacturing Advisory Service (MAS) was introduced by Smith et al. [39] to aid designers in understanding and learning about different processes and their capabilities. The input information to this system included quantity of production, physical size, required tolerances, cost requirements, and overall shape. The system output involved the list of manufacturing alternatives depending on the input data and optimized relationship between process and material combination. According to Boothroyd [40], the consideration of manufacturing and assembly problems is crucial in the initial stages of the product life cycle. This requirement emphasizes the significance of the appropriate MCDM approach in the early stages of product design. Besides, part complexity, shape information, quality requirements, and the manufacturing time as well as cost also contribute significantly to the development of a robust decision-making process in manufacturing [41]. For instance, the decisionmaking process and subsequently the prestige of any organization are gravely affected if they are unable to define a cost model for their product in the initial stages [42]. It further affirms the importance of the cost model in the decision-making process. Feng and Song [43] developed an integrated design and manufacturing object model to guide interoperability of prior design and process planning in Unified ModelLing Language. It comprised of the manufacturing information, including workpiece data, resources of manufacturing, estimated time, and cost. The output of this system consisted of hierarchical manufacturing processes. The efficient and effective application of computer-aided process planning system may be 
limited due to the absence of a flexible and robust MCDM method $[44,45]$. The MCDM methods can be useful in the selection of the best alternative and make the manufacturing process cost-effective. The MCDM can be very helpful in overcoming the challenges related to the integration of computer-aided process planning systems and manufacturing activities [46].

There have been significant contributions, where researchers have proposed different MCDM approaches. However, a methodology, which can compare the various MCDM techniques, is seldom available in the literature in the context of manufacturing process selection. There is still a need for more comparative evaluations of various methods in the context of manufacturing process selection. To overcome this gap in the literature, comparative analysis of the methods in the context of manufacturing process selection is also needed. Therefore, this work develops an approach to assess different selection approaches. The main advantages of the proposed approach are as follows: (1) it can be applied to a complex manufacturing process selection; (2) it has a simpler structure compared to the technique used; (3) it provides overall comparative analysis to assess different selection approaches; (4) it considers the following factors for comparative analysis: number of alternative processes and criteria, agility through the process of decision-making, computational complexity, adequacy in supporting a group decision, and addition or removal of a criterion.

\section{Methodology}

A methodology for comparing MCDM methods and assisting stakeholders to select the best selection tool depending on their application has been presented. In this work, three MCDM methods have been selected based on owing to their popularity, ease of application, and superlative results in earlier works. The selected methods are AHP, TOPSIS, and VIKOR. The different steps for the application of selected methods and their comparative assessment are shown in Figure 1.

\section{MCDM Methods}

The different MCDM tools, which have been utilized in this study, can be described as follows.

4.1. Analytical Hierarchy Process. The AHP can be described as one of the most prominent approaches to assess the analogy between customer needs and design characteristics [47]. To implement the AHP approach, a four-step procedure was established by Saaty [48] and is shown below.

Step 1. Generate a paired comparison matrix. An overall number of $[n(n-1) / 2]$ pairwise comparisons have to be assessed for a cluster with $n$ customer demands. The different attributes are rated on the 9-point Likert scale including their reciprocals as shown in Table 1. A paired comparison matrix is expressed in the following equation:

$$
A=\left[\begin{array}{cccc}
1 & a_{12} & \cdots & a_{1 n} \\
a_{21} & 1 & \cdots & a_{2 n} \\
\cdots & \cdots & \cdots & \cdots \\
a_{n 1} & a_{n 2} & \cdots & 1
\end{array}\right],
$$

where $A$ represents an $n * n$ pairwise matrix of comparison. The values on the right and left sides of the matrix diagonal represent the strength of agreement of $i^{\text {th }}$ element with respect to $j^{\text {th }}$ element. Let $a_{i j}=1 / a_{j i}$, where $i, j=1,2, \ldots, n, a_{i j}>0, i \neq j$.

Step 2. The relative importance of various attributes is computed using the normalization of the geometric mean (NGM) technique. $W_{i}$ symbolizes the degree of importance for the $i$ th customer requirement:

$$
W_{i}=\frac{\left(\prod_{j=1}^{n} a_{i j}\right)^{1 / n}}{\sum_{i=1}^{n}\left(\prod_{j=1}^{n} a_{i j}\right)^{1 / n}}, \quad i, j=1,2, \ldots, n .
$$

Step 3. Consistency of the obtained degree of importance for the attributes. In order to confirm that pairwise comparison is rational and suitable, a consistency test has to be carried out. Let $C$ signify an $n$ dimensional column vector relating to the sum of weighted values for the importance degrees of criteria:

$$
C=\left[c_{i}\right] n * 1=A * W T, \quad i=1,2, \ldots, n,
$$

where

$$
\begin{aligned}
W^{T} & =\left[\begin{array}{cccc}
1 & a_{12} & \cdots & a_{1 n} \\
a_{21} & 1 & \cdots & a_{2 n} \\
\cdots & \cdots & \cdots & \cdots \\
a_{n 1} & a_{n 2} & \cdots & 1
\end{array}\right] \cdot\left[w_{1}, w_{2}, \ldots, w_{n}\right], \\
T & =\left[\begin{array}{l}
c_{1} \\
c_{2} \\
\cdots \\
c_{n}
\end{array}\right] .
\end{aligned}
$$

The consistency values for the customer demand cluster (or the attributes) can be specified by the vector $C V=$ $\left[c v_{i}\right]_{1 * n}$, with a representative element $c v_{i}$ computed as follows:

$$
c v_{i}=\frac{c_{i}}{w_{i}}, \quad i=1,2, \ldots, n
$$

To avoid any inconsistency due to diversified measurement scales in the assessment process, Saaty [48] recommended application of maximal eigenvalue $\lambda_{\max }$ to assess the validity of measurements. The maximal eigenvalue $\lambda_{\max }$ can be determined using the following equation:

$$
\lambda_{\max }=\frac{\sum_{i=1}^{n} c v_{i}}{n}, \quad i=1,2, \ldots, n .
$$

Using $\lambda_{\max }$, a consistency index (CI) can be calculated as follows: 


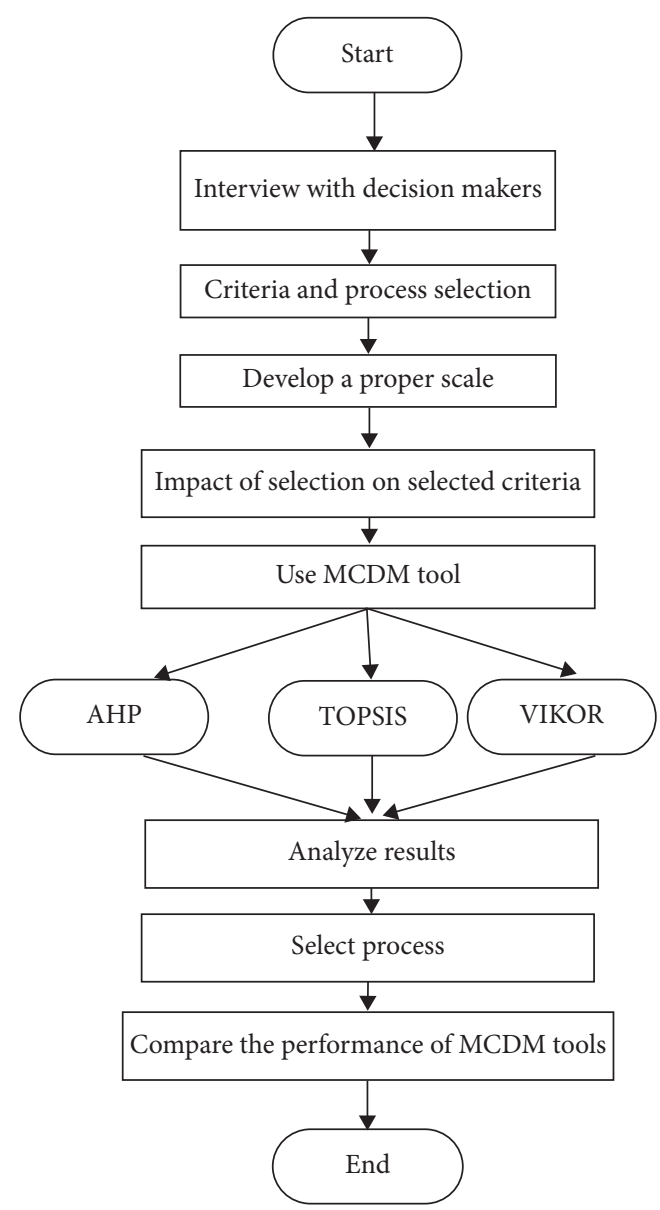

FIGURE 1: Steps for the application of MCDM tools and their performance evaluation.

TABle 1: A 9-point Likert scale.

\begin{tabular}{lc}
\hline Intensity of agreement & Definition of intensity of agreement \\
\hline 1 & Strongly disagree \\
3 & Disagree \\
5 & Somewhat agree \\
7 & Agree \\
9 & Strongly agree \\
$2,4,6$, and 8 & Intermediate values \\
\hline
\end{tabular}

$$
\mathrm{CI}=\frac{\lambda_{\max }-n}{n-1}
$$

The value of $\mathrm{CI}=0$, suggesting that the pairwise comparison is entirely consistent. Note that the closer the maximal eigenvalue is to $n$, the more consistent is assessment. Typically, a consistency ratio (CR) [48] can be used as a guidance value to check for conformity:

$$
\mathrm{CR}=\frac{\mathrm{CI}}{\mathrm{RI}}
$$

RI represents the average random index with the value that is estimated using different orders of the pairwise matrices of comparison. If the CR value is less than 0.1 that is the threshold, then the importance degree evaluation of criteria is assumed to be rational.

Step 4. Define the relative overall importance degrees of different attributes.

4.2. Technique for Order of Preference by Similarity to Ideal Solution. The TOPSIS technique is among the extrusive MCDM methods [49, 50]. According to this method, the best alternative should possess the shortest distance from the positive ideal solution (PIS). It must possess the highest distance from the negative ideal solution (NIS). A set of generated alternatives (say design alternatives), $\mathrm{DA}=$ $\left\{\mathrm{DA}_{r}=1,2, \ldots s\right\}$, is compared with respect to a set of customer needs, $R=\left\{R_{i}, i=1,2, \ldots n\right\}$ in this approach. Let DAR represent an $i * \mathrm{r}$ multiple criteria decision matrix and the element $\mathrm{DAR}_{i, r}$ indicates the performance rating of design alternative $\mathrm{DA}_{r}$ with regard to customer requirement $R_{i}$. DAR $=\left\{a_{i, r}, i=1,2, \ldots n ; r=1,2, \ldots s\right\}$. The various steps for TOPSIS approach can be described as follows:

Step 1. Development of normalized decision matrix (NDM). The NDM is employed to express the relative performance of generated DAs, along with element normalized decision matrix $\mathrm{NDM}_{i, r}$ :

$$
\mathrm{NDM}_{i, r}=\frac{a_{i . r}}{\sqrt{\sum_{r=1}^{s} a_{i . r}^{2}}} .
$$

Step 2. Computation of weighted decision matrix (WDM). Let $\mathrm{WDM}=\left\{b_{i, r}, i=1,2, \ldots n ; r=1,2, \ldots s\right\}$ :

$$
b_{i, r}=W_{i} \frac{a_{i . r}}{\sqrt{\sum_{r=1}^{s} a_{i . r}^{2}}} .
$$

$W_{i}$ represents the importance degree for $i^{\text {th }}$ requirement of customer.

Step 3. Definition of PIS and NIS based on WDM. The PIS and NIS can be shown as follows:

$$
\begin{aligned}
& \mathrm{PIS}=\left\{\left(\begin{array}{c}
\max \\
r
\end{array} b_{i, r} \mid i \in J\right) \operatorname{or}\left(\begin{array}{c}
\min \\
r
\end{array} b_{i, r} \mid i \in J^{\prime}\right) \mid r=1,2, \ldots, s\right\}=b_{1}^{+}, b_{2}^{+}, \ldots, b_{n}^{+}, \\
& \mathrm{NIS}=\left\{\left(\begin{array}{c}
\min \\
r
\end{array} b_{i, r} \mid i \in J\right) \operatorname{or}\left(\begin{array}{c}
\max \\
r
\end{array} b_{i, r} \mid i \in J^{\prime}\right) \mid r=1,2, \ldots, s\right\}=b_{1}^{-}, b_{2}^{-}, \ldots, b_{n}^{-},
\end{aligned}
$$


where $J=\{i=1,2, \ldots, n$ and $i$ is related with profitable requirements of customer of $\left.b_{i, r}\right\}$, and $J^{\prime}=\{i=1,2, \ldots n$ and $i$ is related to cost criteria of $b_{i, r}$.

Step 4. Calculation of distance of separation for every option from PIS and NIS. In this study, the Euclidean distance technique was used. Let $b_{r}^{-}$and $b_{r}^{+}$specify the distance of $i$ th design alternative from NIS and PIS, respectively:

$$
\begin{aligned}
& b_{r}^{+}=\sqrt{\sum_{i=1}^{n}\left(b_{i, r}-b_{1}^{+}\right)^{2},} \quad r=1,2, \ldots, s, \\
& b_{r}^{-}=\sqrt{\sum_{i=1}^{n}\left(b_{i, r}-b_{1}^{-}\right)^{2}}, \quad r=1,2, \ldots, s .
\end{aligned}
$$

Step 5. Computation of the relative similarity or closeness degree to the ideal solution for each competitive design alternative. RC represents an $s$-dimensional column vector determining the coefficient of relative closeness to the ideal solution for competitive design alternatives, with typical element $\mathrm{RC}_{r}$ :

$\mathrm{RC}_{r}=\frac{b_{r}^{-}}{b_{r}^{+}+b_{r}^{-}}, \quad r=1,2, \ldots, s$ and $0 \leq \mathrm{RC}_{r} \leq 1$.

Step 6. Rank the preference order of competitive design alternatives depending on relative closeness with the ideal solution, where the maximum value of relative closeness indicates a higher-ranking order among competitive design options and should be used as a preferred design alternative.

4.3. VIKOR: Stepwise Procedure. The MCDM approaches can be identified as one of the most useful methods for dealing with a dispute between various engineering and management subjects [51]. One of the MCDM approaches is the VIKOR method, which can be recognized as a flexible ranking method to get the best decision-making procedure [52]. The implementation of the VIKOR method focuses on ranking and choosing from a group of alternatives in the existence of contradictions [53]. The basic procedures of VIKOR technique exhibited as follows:

Step 1. Provide values for all linguistic variables in relevance to feasible alternatives of process. Subsequently, for each criterion, a matrix of alternatives has to be developed.

Step 2. Generate a matrix of decision. The alternative ratings are collected through expert's ratings, and then, matrix of decision is generated by the following equation:

$$
A=\frac{1}{k} \sum_{i=1}^{n} A_{i j}, \quad \text { for all } j=1,2, \ldots, m,
$$

where $k$ is the number of decision maker, $i$ is the number of alternatives, and $j$ is the number of criteria.
Step 3. Identify best $f_{b}^{*}$ and worst $f_{b}^{-}$from criterion rating values, where $b=1,2, \ldots, n$. The following equations are used to compute the best $f_{b}^{*}$ and worst $f_{b}^{-}$values:

$$
\begin{aligned}
& f_{b}^{*}=\max \left(f_{a b}\right), \\
& f_{b}^{-}=\max \left(f_{a b}\right),
\end{aligned}
$$

where $f_{b}^{*}$ is the PIS for the $b^{\text {th }}$ criterion and $f_{b}^{-}$is the NIS for the $b^{\text {th }}$ criterion.

Step 4. Compute values of $S_{a}$ and $R_{a}$ for $a=1,2, \ldots, m$ using the following equations:

$$
\begin{aligned}
& S_{a}=\sum_{b=1}^{n} W_{b}\left[\frac{f_{b}^{*}-f_{a b}}{f_{b}^{*}-f_{b}^{-}}\right], \\
& R_{a}=\max _{b}\left[W_{b}\left[\frac{f_{b}^{*}-f_{a b}}{f_{b}^{*}-f_{b}^{-}}\right]\right],
\end{aligned}
$$

where $S_{a}$ represents the rate of distance to PIS, i.e., maximum "group utility of majority," $R_{a}$ denotes the distance rate to NIS, i.e., minimum "individual regret of opponent," and $W_{b}$ represents each criterion weight that computed by AHP.

Step 5. Compute the aggregating index, i.e., final negotiation solution $Q_{a}$ for $a=1,2, \ldots m$ through equation (21). The best alternative has the least $Q_{a}$ value:

$$
Q_{a}=v \frac{S_{a}-S^{*}}{S^{-}-S^{*}}+(1-v) \frac{R_{a}-R^{*}}{R^{-}-R^{*}},
$$

where

$$
\begin{aligned}
S^{-} & =\max _{a} S_{a} S^{-}, \\
S^{*} & =\min _{a} S_{a} S^{*}, \\
R^{-} & =\max _{a} R_{a} R^{-}, \\
R^{*} & =\min _{a} R_{a} R^{*} .
\end{aligned}
$$

The solutions, which achieve $\max _{a} S_{a}$, point at the "maximum group majority," while the solutions which obtain $\min _{a} R_{a}$ indicate "minimum individual regret" of alternative. The weight of the path of action or maximum set usefulness is represented by $v$. The $(1-v)$ points to the weight of individual contrition. The value of $v$ in this study is 0.5 .

Step 6. Based on $Q_{a}$ values, rank the alternatives.

Step 7. The best negotiation solution has a minimum value of $Q$ and can be recommended if the following two conditions are satisfied:

(1) If $Q\left(A^{(2)}\right)-Q\left(A^{(1)}\right) \geq 1 / n-1$, then the alternative $Q\left(A^{(1)}\right)$ represents a convenient feature, where $n$ is the number of alternatives and $Q\left(A^{(1)}\right)$ and $Q\left(A^{(1)}\right)$ are the alternatives

(2) $Q\left(A^{(1)}\right)$ is steady and constant in decision-making if it is identified as best in $S_{a}$ and $R_{a}$ 
Step 8. The alternative $\left(A^{(m)}\right)$ that has the smallest value of $Q_{a}$ with regard to the conditions mentioned above is the best alternative, where " $m$ " represents the number of alternatives.

\section{Case Study}

The case study employed in this work included a submersible water pump driven by a built-in submersible motor driving multistage impeller/diffuser sets. The product is assembled on a common shaft. Moreover, the pump power performance increases by an increase in the number of stages and motor horsepower simultaneously. Hence, the selected product consisted of two subassemblies enclosed with two end supports, which are enclosed with stainless steel tube. The main function of the stainless steel tube is holding either motor-stator or multistage impeller/diffuser set. The selected part is one of the motor supports that assembled with the motor subassembly unit. Figure 2 shows the 3D CAD model for the selected part.

The criteria used to evaluate and identify the best manufacturing process were categorized into productivity, accuracy, complexity, flexibility, material utilization, quality, and operation cost [54]. Five manufacturing processes were considered, including gravity die casting, investment casting, pressure die casting, sand casting, and additive manufacturing. The number of experts participated in the evaluation process is five. Figure 3 illustrates the criteria for the manufacturing process evaluation.

Recently, the AHP was one of the MCDM approaches employed to solve the given selection problem. With AHP, the preference degree of decision makers/stakeholders regarding the choice of manufacturing process was quantified through pairwise comparisons. The pairwise comparisons were conducted based on the developed AHP methodology in [55]. Table 2 shows a matrix of evaluation relevant to the main criteria. By using the AHP method, the weight vectors for the main criteria and overall weight vectors are computed and are shown in Table 3. Table 4 shows the summary of the results. It is clear that the most important criterion for users with regard to the selected material is accuracy. According to the ranking of the manufacturing processes, pressure die casting is the best process for this case study with the highest overall score of 0.297. Although pressure die casting did not have the highest weight with respect to the operation cost criteria, it is still the best manufacturing process among all of the competing manufacturing processes with respect to the overall evaluation.

Based on the linguistic terms, the decision makers performed assessment of the weight of the criteria and the ratings of manufacturing processes, as indicated in Table 5. Table 6 indicates NDM of aggregated ratings of the alternative manufacturing process. The weighted NDM is shown in Table 7. The PIS and NIS are expressed as follows:

$$
\begin{aligned}
\text { PIS } & =\{1,1,1,1,1\}, \\
\text { NIS } & =\{0,0,0,0,0\} .
\end{aligned}
$$

The distances $b_{r}^{+}$and $b_{r}^{-}$of ratings for each manufacturing process from $A^{+}$and $A^{-}$, calculated based on equations (9)-(14), are shown in Table 8 and Table 9, respectively. The thorough performance of each manufacturing process is shown by the relative closeness, $\mathrm{RCi}$, which is calculated in equation (15) and illustrated in Table 10. Finally, this calculation leads to outranking shown in Table 10, which means that pressure die casting is the best manufacturing process.

The assessment matrix of criteria and manufacturing processes alternatives was generated through a scale mentioned in Table 1. The collected matrix for weights of manufacturing process alternatives was calculated using (16) and is illustrated in Table 11 . Next, the best $f_{b}^{*}$ and worst $f_{b}^{*}$ values of all criteria were computed using equations (17) and (18). Then, the $S$ and $R$ values were computed by using equations (19) and (20). The $Q$ values for all manufacturing processes were computed by using equation (21), and the maximum group utility $v=0.5$ was considered and is displayed in Table 12. The manufacturing processes were ranked according to $S, R$, and $Q$ in descending order. According to $Q_{a}$ values, the chosen best manufacturing process has been performed and is displayed in Table 13.

As described in Section 4.3, " $S$ " denotes PIS, " $R$ " denotes NIS, and " $Q$ " denotes optimal compromise solution. Thus, the decision-making may be carried out by ordering the values of $Q$ in descending order. Based on $Q$ values, the descending order of manufacturing process alternatives causes the following ranking: pressure die casting $>$ investment casting $>$ gravity die casting $>$ additive manufacturing $>$ sand casting. Therefore, the best alternative is pressure die casting. Moreover, both conditions in VIKOR method (in Step 7) were attained that means $Q$ (pressure die casting)$Q$ (investment casting) $\geq 1 / 5-1$ and, similarly, the pressure die casting was highly ranked by $R$ and $S$ that guaranteed decision-making stability.

Finally, the alternative manufacturing processes were ranked based on their respective weights for AHP, TOPSIS, and VIKOR with regard to improvement criteria opted by decision maker (see Table 14). For the case study, presented approach recommended pressure die casting. It must be noted that ranking of manufacturing processes alternatives is closely dependent on obtained weights using pairwise comparison of selected criteria. Thus, if the agreement of selected is changed by decision maker, the ranking of identified alternative manufacturing processes will be influenced and changed directly.

\section{Comparative Evaluation of Suggested Approaches}

The comparison of all the suggested methods was made according to a set of required characteristics which are crucial to overcome the issue of choosing manufacturing processes. The following factors were considered [10]: adequacy to changes in alternatives or criteria, agility during the decision-making process, computational complexity, adequacy in supporting group decision-making, number of 

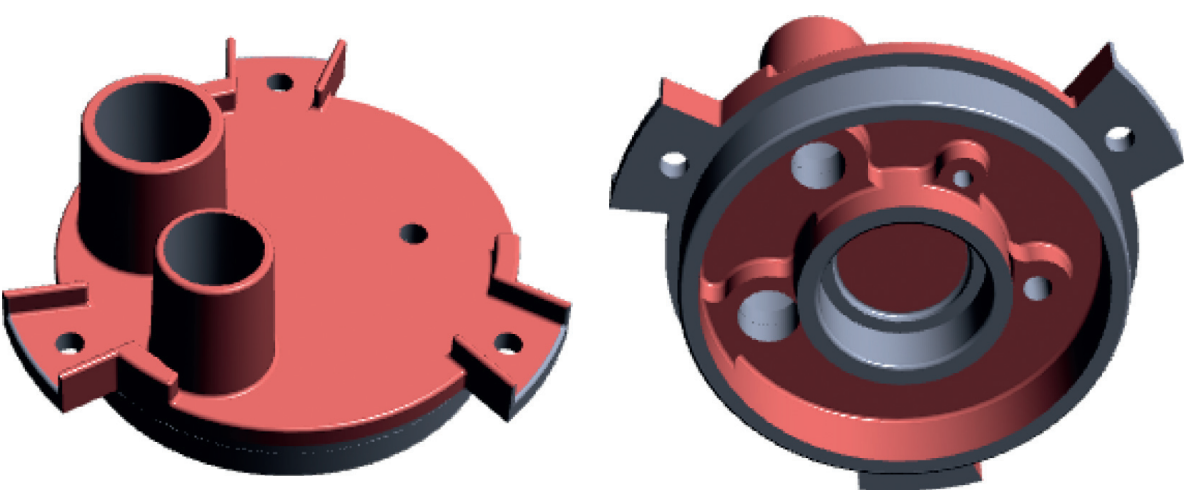

FIGURE 2: Case study: product selected for the study.

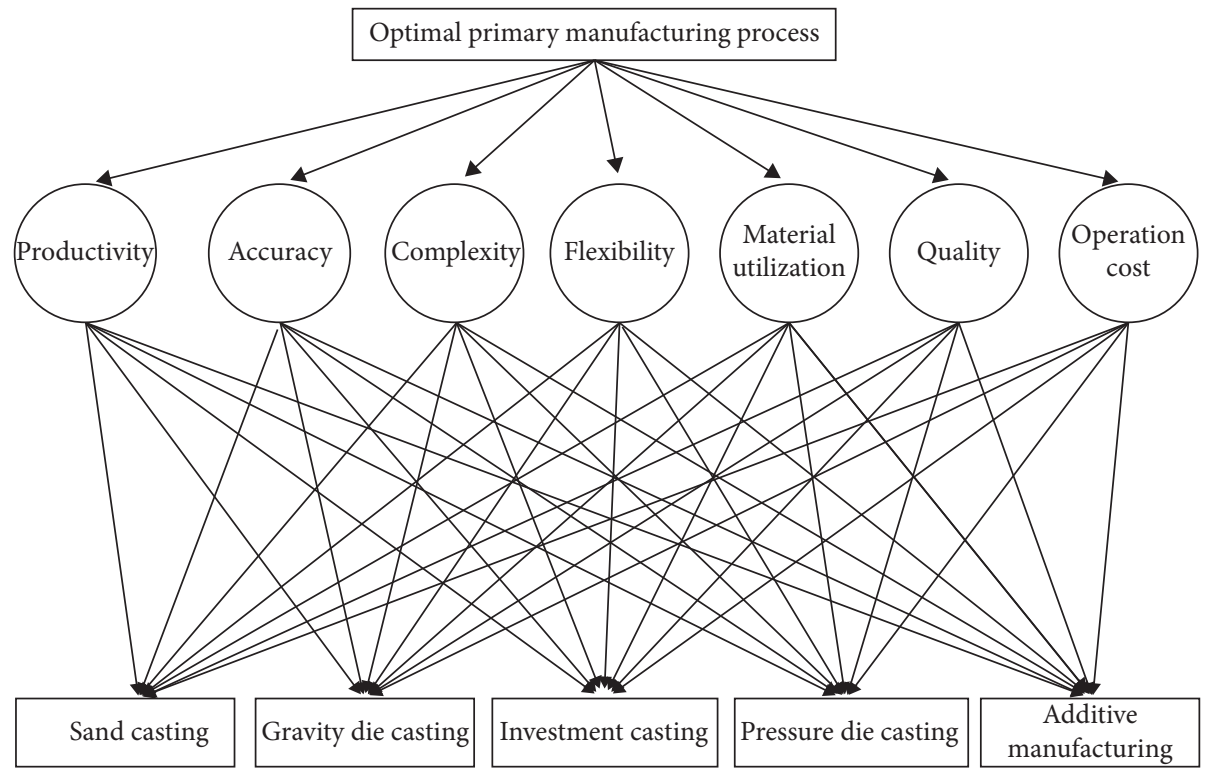

FIGURE 3: Attributes used for the manufacturing process evaluation.

TABLE 2: The main criteria evaluation matrix.

\begin{tabular}{|c|c|c|c|c|c|c|c|c|c|c|}
\hline$C_{i j}$ & Productivity & Accuracy & Complexity & Flexibility & $\begin{array}{c}\text { Material } \\
\text { utilization }\end{array}$ & Quality & $\begin{array}{c}\text { Operation } \\
\text { cost }\end{array}$ & Priority & $\begin{array}{c}\text { Principal } \\
\text { eigen value }\end{array}$ & $\begin{array}{c}\text { Consistency } \\
\text { ratio } \mathrm{CR}\end{array}$ \\
\hline Productivity & 1 & 1 & 3 & 5 & 2 & 4 & 3 & 0.264454 & 7.53507 & 0.066568 \\
\hline Accuracy & & 1 & 5 & 6 & 3 & 5 & 3 & 0.32392 & & \\
\hline Complexity & & & 1 & 1 & 3 & 2 & 1 & 0.104459 & & \\
\hline Flexibility & & & & 1 & 2 & 3 & 2 & 0.102623 & & \\
\hline $\begin{array}{l}\text { Material } \\
\text { utilization }\end{array}$ & & & & & 1 & 2 & 2 & 0.086151 & & \\
\hline Quality & & & & & & 1 & 1 & 0.050267 & & \\
\hline $\begin{array}{l}\text { Operation } \\
\text { cost }\end{array}$ & & & & & & & 1 & 0.068127 & & \\
\hline
\end{tabular}

alternative manufacturing processes as well as criteria, and uncertainty modelling.

6.1. Agility in Decision Process. This factor assesses the number of judgments required from decision makers for all approaches. Let $p$ be the number of manufacturing processes and $c$ be the criteria number, in the AHP approach, where the required judgment number for a matrix of decision $A_{i x i}$ is as follows:

$$
J_{A_{i, i}}=i \frac{i-1}{2}
$$


TABLE 3: The original data of rating manufacturing process in the AHP.

\begin{tabular}{|c|c|c|c|c|c|c|c|c|c|}
\hline Criteria & $C_{i j}$ & $\begin{array}{c}\text { Sand } \\
\text { casting }\end{array}$ & $\begin{array}{c}\text { Gravity } \\
\text { die } \\
\text { casting }\end{array}$ & $\begin{array}{c}\text { Investment } \\
\text { casting }\end{array}$ & $\begin{array}{c}\text { Pressure } \\
\text { die casting }\end{array}$ & $\begin{array}{c}\text { Additive } \\
\text { manufacturing }\end{array}$ & Priority & $\begin{array}{c}\text { Principal } \\
\text { eigen value }\end{array}$ & $\begin{array}{c}\text { Consistency } \\
\text { ratio } \mathrm{CR}\end{array}$ \\
\hline \multirow{5}{*}{ Productivity } & \multirow{2}{*}{$\begin{array}{l}\text { Sand casting } \\
\text { Gravity die } \\
\text { casting }\end{array}$} & \multirow[t]{5}{*}{1} & $1 / 2$ & 1 & $1 / 9$ & 5 & 0.1042 & \multirow[t]{5}{*}{5.390771} & \multirow[t]{5}{*}{0.086873} \\
\hline & & & 1 & 4 & $1 / 4$ & 5 & 0.2095 & & \\
\hline & $\begin{array}{l}\text { Investment } \\
\text { casting }\end{array}$ & & & 1 & $1 / 4$ & 3 & 0.0941 & & \\
\hline & $\begin{array}{l}\text { Pressure die } \\
\text { casting }\end{array}$ & & & & 1 & 7 & 0.5529 & & \\
\hline & $\begin{array}{c}\text { Additive } \\
\text { manufacturing }\end{array}$ & & & & & 1 & 0.0394 & & \\
\hline \multirow{5}{*}{ Accuracy } & Sand casting & 1 & $1 / 2$ & $1 / 2$ & $1 / 5$ & $1 / 5$ & 0.0736 & \multirow[t]{5}{*}{5.337901} & \multirow{5}{*}{0.075119} \\
\hline & $\begin{array}{l}\text { Gravity die } \\
\text { casting }\end{array}$ & & 1 & $1 / 2$ & $1 / 2$ & 2 & 0.1794 & & \\
\hline & $\begin{array}{l}\text { Investment } \\
\text { casting }\end{array}$ & & & 1 & 1 & 2 & 0.2669 & & \\
\hline & $\begin{array}{l}\text { Pressure die } \\
\text { casting }\end{array}$ & & & & 1 & 2 & 0.3083 & & \\
\hline & $\begin{array}{c}\text { Additive } \\
\text { manufacturing }\end{array}$ & & & & & 1 & 0.1718 & & \\
\hline \multirow{5}{*}{ Complexity } & Sand casting & 1 & 6 & 1 & 5 & $1 / 3$ & 0.2582 & \multirow[t]{5}{*}{5.399496} & \multirow[t]{5}{*}{0.088812} \\
\hline & $\begin{array}{l}\text { Gravity die } \\
\text { casting }\end{array}$ & & 1 & $1 / 2$ & 1 & $1 / 4$ & 0.0734 & & \\
\hline & $\begin{array}{l}\text { Investment } \\
\text { casting }\end{array}$ & & & 1 & 6 & 1 & 0.2584 & & \\
\hline & $\begin{array}{l}\text { Pressure die } \\
\text { casting }\end{array}$ & & & & 1 & $1 / 3$ & 0.0644 & & \\
\hline & $\begin{array}{c}\text { Additive } \\
\text { manufacturing }\end{array}$ & & & & & 1 & 0.3455 & & \\
\hline \multirow{5}{*}{ Flexibility } & Sand casting & 1 & 4 & 2 & 5 & $1 / 2$ & 0.3151 & \multirow[t]{5}{*}{5.368257} & \multirow[t]{5}{*}{0.081868} \\
\hline & $\begin{array}{l}\text { Gravity die } \\
\text { casting }\end{array}$ & & 1 & 1 & 2 & $1 / 2$ & 0.1269 & & \\
\hline & $\begin{array}{l}\text { Investment } \\
\text { casting }\end{array}$ & & & 1 & 4 & $1 / 2$ & 0.1694 & & \\
\hline & $\begin{array}{l}\text { Pressure die } \\
\text { casting }\end{array}$ & & & & 1 & $1 / 2$ & 0.0746 & & \\
\hline & $\begin{array}{c}\text { Additive } \\
\text { manufacturing }\end{array}$ & & & & & 1 & 0.3141 & & \\
\hline \multirow{5}{*}{$\begin{array}{l}\text { Material } \\
\text { utilization }\end{array}$} & Sand casting & 1 & 1 & $1 / 3$ & $1 / 5$ & $1 / 8$ & 0.0645 & \multirow[t]{5}{*}{5.427601} & \multirow[t]{5}{*}{0.09506} \\
\hline & $\begin{array}{l}\text { Gravity die } \\
\text { casting }\end{array}$ & & 1 & 1 & 1 & $1 / 5$ & 0.1229 & & \\
\hline & $\begin{array}{l}\text { Investment } \\
\text { casting }\end{array}$ & & & 1 & 2 & 1 & 0.2373 & & \\
\hline & $\begin{array}{l}\text { Pressure die } \\
\text { casting }\end{array}$ & & & & 1 & $1 / 3$ & 0.1588 & & \\
\hline & $\begin{array}{c}\text { Additive } \\
\text { manufacturing }\end{array}$ & & & & & 1 & 0.4165 & & \\
\hline \multirow{5}{*}{ Quality } & Sand casting & 1 & $1 / 5$ & $1 / 5$ & $1 / 5$ & $1 / 4$ & 0.0491 & \multirow[t]{5}{*}{5.071013} & \multirow[t]{5}{*}{0.015787} \\
\hline & $\begin{array}{l}\text { Gravity die } \\
\text { casting }\end{array}$ & & 1 & 1 & 1 & 1 & 0.2359 & & \\
\hline & $\begin{array}{l}\text { Investment } \\
\text { casting }\end{array}$ & & & 1 & 2 & 2 & 0.3148 & & \\
\hline & $\begin{array}{l}\text { Pressure die } \\
\text { casting }\end{array}$ & & & & 1 & 1 & 0.2049 & & \\
\hline & $\begin{array}{c}\text { Additive } \\
\text { manufacturing }\end{array}$ & & & & & 1 & 0.1952 & & \\
\hline
\end{tabular}


TABle 3: Continued.

\begin{tabular}{|c|c|c|c|c|c|c|c|c|c|}
\hline Criteria & $C_{i j}$ & $\begin{array}{l}\text { Sand } \\
\text { casting }\end{array}$ & $\begin{array}{c}\text { Gravity } \\
\text { die } \\
\text { casting }\end{array}$ & $\begin{array}{l}\text { Investment } \\
\text { casting }\end{array}$ & $\begin{array}{c}\text { Pressure } \\
\text { die casting }\end{array}$ & $\begin{array}{c}\text { Additive } \\
\text { manufacturing }\end{array}$ & Priority & $\begin{array}{l}\text { Principal } \\
\text { eigen value }\end{array}$ & $\begin{array}{c}\text { Consistency } \\
\text { ratio } \mathrm{CR}\end{array}$ \\
\hline \multirow{5}{*}{$\begin{array}{l}\text { Operation } \\
\text { cost }\end{array}$} & \multirow{2}{*}{$\begin{array}{l}\text { Sand casting } \\
\text { Gravity die } \\
\text { casting }\end{array}$} & 1 & 1 & 1 & 1 & 1 & 0.1917 & 5.216373 & 0.048102 \\
\hline & & & 1 & $1 / 2$ & $1 / 2$ & 2 & 0.1732 & & \\
\hline & $\begin{array}{l}\text { Investment } \\
\text { casting }\end{array}$ & & & 1 & 2 & 2 & 0.2909 & & \\
\hline & $\begin{array}{l}\text { Pressure die } \\
\text { casting }\end{array}$ & & & & 1 & 1 & 0.197 & & \\
\hline & $\begin{array}{c}\text { Additive } \\
\text { manufacturing }\end{array}$ & & & & & 1 & 0.1472 & & \\
\hline
\end{tabular}

TABLE 4: AHP results for the case study.

\begin{tabular}{lcccccc}
\hline Criteria & Weight & Sand casting & Gravity die casting & Investment casting & Pressure die casting & Additive manufacturing \\
\hline Productivity & 0.264454 & 0.104152 & 0.209493 & 0.094062 & 0.552875 & 0.039418 \\
Accuracy & 0.32392 & 0.073584 & 0.179427 & 0.266929 & 0.308276 & 0.171784 \\
Complexity & 0.104459 & 0.258235 & 0.073424 & 0.258436 & 0.064398 & 0.345507 \\
Flexibility & 0.102623 & 0.315072 & 0.126903 & 0.169364 & 0.074594 & 0.314066 \\
Material utilization & 0.086151 & 0.064543 & 0.122857 & 0.237289 & 0.158783 & 0.416528 \\
Quality & 0.050267 & 0.049112 & 0.235939 & 0.314837 & 0.204899 & 0.195213 \\
Operation cost & 0.068127 & 0.1917 & 0.17317 & 0.290888 & 0.197023 & 0.14722 \\
Total weighted & 1.000001 & 0.13177645 & 0.168455972 & 0.211801245 & 0.297850336 & 0.190116964 \\
Rank & 5 & 4 & 2 & 1 & 3 \\
\hline
\end{tabular}

TABLE 5: The assessment of decision makers for the criteria and the manufacturing processes.

\begin{tabular}{lccccccc}
\hline & Productivity & Accuracy & Complexity & Flexibility & Material utilization & Quality & Operation cost \\
\hline Sand casting & 5 & 3 & 9 & 9 & 3 & 6 & 2 \\
Gravity die casting & 9 & 8 & 3 & 6 & 6 & 9 & 8 \\
Investment casting & 4 & 9 & 9 & 8 & 9 & 9 & 9 \\
Pressure die casting & 9 & 9 & 4 & 8 & 9 & 9 & 9 \\
Additive manufacturing & 2 & 8 & 9 & 9 & 4 & 9 \\
Weights of criteria & 9 & 9 & 5 & 5 & & 3 \\
\hline
\end{tabular}

TABLE 6: Normalized decision matrix of the collected ratings of the manufacturing process alternatives.

\begin{tabular}{lcccccc}
\hline Criteria & $\begin{array}{c}A_{1} \text { (sand } \\
\text { casting) }\end{array}$ & $\begin{array}{c}A_{2} \text { (gravity die } \\
\text { casting) }\end{array}$ & $\begin{array}{c}A_{3} \text { (investment } \\
\text { casting) }\end{array}$ & $\begin{array}{c}A_{4} \text { (pressure die } \\
\text { casting) }\end{array}$ & $\begin{array}{c}A_{5} \text { (additive } \\
\text { manufacturing) }\end{array}$ & $\begin{array}{c}\text { Weights of } \\
\text { criteria }\end{array}$ \\
\hline Productivity & 0.555556 & 1 & 0.444444 & 1 & 0.222222 & 1 \\
Accuracy & 0.333333 & 0.888889 & 1 & 1 & 0.444444 & 0.888889 \\
Complexity & 1 & 0.333333 & 1 & 0.888889 & 1 & 1 \\
Flexibility & 1 & 0.666667 & 0.888889 & 0.888889 & 1 & 0.555556 \\
Material & 0.333333 & 0.666667 & 1 & 1 & 1 & 0.455556 \\
utilization & 0.222222 & 1 & 1 & 1 & 1 & 0.333333 \\
Quality & 0.666667 & 0.888889 & 1 & & & 1 \\
Operation cost & & & & & & 0.333333 \\
\hline
\end{tabular}

For each decision criterion, there is $c$ matrix of size $p \times p$; moreover, the weight of the criteria needs a decision matrix of size $c \times c$. Therefore, the total required number of judgments is given in the following equation:

$$
J_{p, m}^{\mathrm{AHP}}=c \frac{c-1}{2}+c\left(p \frac{p-1}{2}\right) .
$$

In the TOPSIS and VIKOR approaches, for each of the $p$ alternative, there is a need a total of $c$ judgments; moreover, the weight of the criteria needs $c$ judgments. Therefore, the total required number of judgments can be represented as follows:

$$
J_{p, c}^{\mathrm{TOPSIS} \text { or VIKOR }}=c+p c .
$$

In the present case study, TOPSIS and VIKOR required 42 judgments, whereas AHP required 91 judgments. Therefore, it can be found that VIKOR and TOPSIS approaches performed better than the AHP approach 
TABLE 7: Weighted NDM.

\begin{tabular}{|c|c|c|c|c|c|}
\hline Criteria & $A_{1}$ & $A_{2}$ & $A_{3}$ & $A_{4}$ & $A_{5}$ \\
\hline Productivity & 0.555556 & 1 & 0.444444 & 1 & 0.222222 \\
\hline Accuracy & 0.333333 & 0.888889 & 1 & 1 & 0.888889 \\
\hline Complexity & 0.555556 & 0.185185 & 0.555556 & 0.246914 & 0.555556 \\
\hline Flexibility & 0.555556 & 0.37037 & 0.493827 & 0.493827 & 0.555556 \\
\hline Material utilization & 0.148148 & 0.296296 & 0.444444 & 0.395062 & 0.444444 \\
\hline Quality & 0.074074 & 0.333333 & 0.333333 & 0.333333 & 0.333333 \\
\hline Operation cost & 0.222222 & 0.296296 & 0.333333 & 0.333333 & 0.333333 \\
\hline
\end{tabular}

TABLE 8: Rating of each alternative from $A^{+}$(PIS).

\begin{tabular}{|c|c|c|c|c|c|}
\hline Criteria & $d\left(A_{1}, A^{+}\right)$ & $d\left(A_{2}, A^{+}\right)$ & $d\left(A_{3}, A^{+}\right)$ & $d\left(A_{4}, A^{+}\right)$ & $d\left(A_{5}, A^{+}\right)$ \\
\hline Productivity & 0.444444 & 0 & 0.555556 & 0 & 0.777778 \\
\hline Accuracy & 0.666667 & 0.111111 & 0 & 0 & 0.111111 \\
\hline Complexity & 0.444444 & 0.814815 & 0.444444 & 0.753086 & 0.444444 \\
\hline Flexibility & 0.444444 & 0.62963 & 0.506173 & 0.506173 & 0.444444 \\
\hline Material utilization & 0.851852 & 0.703704 & 0.555556 & 0.604938 & 0.555556 \\
\hline Quality & 0.925926 & 0.666667 & 0.666667 & 0.666667 & 0.666667 \\
\hline Operation cost & 0.777778 & 0.703704 & 0.666667 & 0.666667 & 0.666667 \\
\hline$b_{r}^{+}$ & 4.555556 & 3.62963 & 3.395062 & 3.197531 & 3.666667 \\
\hline
\end{tabular}

TABLE 9: Rating of each alternative from $A^{-}$(NIS).

\begin{tabular}{|c|c|c|c|c|c|}
\hline Criteria & $d\left(A_{1}, A^{-}\right)$ & $d\left(A_{2}, A^{-}\right)$ & $d\left(A_{3}, A^{-}\right)$ & $d\left(A_{4}, A^{-}\right)$ & $d\left(A_{5}, A^{-}\right)$ \\
\hline Productivity & 0.555556 & 1 & 0.444444 & 1 & 0.222222 \\
\hline Accuracy & 0.333333 & 0.888889 & 1 & 1 & 0.888889 \\
\hline Complexity & 0.555556 & 0.185185 & 0.555556 & 0.246914 & 0.555556 \\
\hline Flexibility & 0.555556 & 0.37037 & 0.493827 & 0.493827 & 0.555556 \\
\hline Material utilization & 0.148148 & 0.296296 & 0.444444 & 0.395062 & 0.444444 \\
\hline Quality & 0.074074 & 0.333333 & 0.333333 & 0.333333 & 0.333333 \\
\hline Operation cost & 0.222222 & 0.296296 & 0.333333 & 0.333333 & 0.333333 \\
\hline$b_{r}^{-}$ & 2.444444 & 3.37037 & 3.604938 & 3.802469 & 3.333333 \\
\hline
\end{tabular}

TABLE 10: Outranking of alternative manufacturing processes based on TOPSIS.

\begin{tabular}{|c|c|c|c|c|}
\hline Manufacturing processes & $b_{r}^{+}$ & $b_{r}^{-}$ & $\mathrm{RCi}$ & Rank \\
\hline$A_{1}$ (sand casting) & 4.555556 & 2.444444 & 0.349206 & 5 \\
\hline$A_{2}$ (gravity die casting) & 3.62963 & 3.37037 & 0.481481 & 3 \\
\hline$A_{3}$ (investment casting) & 3.395062 & 3.604938 & 0.514991 & 2 \\
\hline$A_{4}$ (pressure die casting) & 3.197531 & 3.802469 & 0.54321 & 1 \\
\hline$A_{5}$ (additive manufacturing) & 3.666667 & 3.333333 & 0.47619 & 4 \\
\hline
\end{tabular}

TABle 11: Collected decision matrix ratings for manufacturing processes.

\begin{tabular}{|c|c|c|c|c|c|c|c|}
\hline$C_{i j}$ & Productivity & Accuracy & Complexity & Flexibility & Material utilization & Quality & Operation cost \\
\hline Sand casting & 5 & 3 & 9 & 9 & 3 & 2 & 6 \\
\hline Gravity die casting & 9 & 8 & 3 & 6 & 6 & 9 & 8 \\
\hline Investment casting & 4 & 9 & 9 & 8 & 9 & 9 & 9 \\
\hline Pressure die casting & 9 & 9 & 4 & 8 & 8 & 9 & 9 \\
\hline Additive manufacturing & 2 & 8 & 9 & 9 & 9 & 9 & 9 \\
\hline Weight of criteria & 9 & 9 & 5 & 5 & 4 & 3 & 3 \\
\hline$f_{b}^{*}$ & 9 & 9 & 9 & 9 & 9 & 9 & 9 \\
\hline$f_{b}^{-}$ & 2 & 3 & 3 & 6 & 3 & 2 & 6 \\
\hline
\end{tabular}


TABLE 12: $S, R$, and $Q$ values for manufacturing processes.

\begin{tabular}{lccc}
\hline$C_{i j}$ & $S$ & $R$ & $Q_{a}$ \\
\hline Sand casting & 24.14 & 9 & 1 \\
Gravity die casting & 14.50 & 5 & 0.31 \\
Investment casting & 8.10 & 6.43 & 0.28 \\
Pressure die casting & 6.50 & 4.17 & 0 \\
Additive manufacturing & 10.50 & 9 & 0.61 \\
\hline & $S^{-}=24.14$ & $R^{-}=9$ & \\
& $S^{*}=6.50$ & $R^{*}=4.17$ & \\
\hline
\end{tabular}

TABLE 13: Ranking of manufacturing processes depending on $S, R$, and $Q$.

\begin{tabular}{lcccccc}
\hline$C_{i j}$ & $S$ & Rank & $R$ & Rank & $Q_{a}$ & Rank \\
\hline Sand casting & 24.14 & 5 & 9 & 5 & 1 & 5 \\
Gravity die casting & 14.50 & 4 & 5 & 2 & 0.31 & 3 \\
Investment casting & 8.10 & 2 & 6.43 & 3 & 0.28 & 2 \\
Pressure die casting & 6.50 & 1 & 4.17 & 1 & 0 & 1 \\
Additive manufacturing & 10.50 & 3 & 9 & 4 & 0.61 & 4 \\
\hline
\end{tabular}

TABLE 14: Overall manufacturing process scores using AHP and TOPSIS.

\begin{tabular}{lcccccc}
\hline $\begin{array}{l}\text { Manufacturing } \\
\text { processes }\end{array}$ & \multicolumn{2}{c}{ AHP } & \multicolumn{2}{c}{ TOPSIS } & \multicolumn{2}{c}{ VIKOR } \\
Score & Rank & Score & Rank & Score & Rank \\
\hline $\begin{array}{l}\text { Sand casting } \\
\begin{array}{l}\text { Gravity die } \\
\text { casting }\end{array}\end{array}$ & 0.131776 & 5 & 0.349206 & 5 & 1 & 5 \\
$\begin{array}{l}\text { Investment } \\
\text { casting }\end{array}$ & 0.168456 & 4 & 0.481481 & 3 & 0.31 & 3 \\
$\begin{array}{l}\text { Pressure die } \\
\text { casting }\end{array}$ & 0.211801 & 2 & 0.514991 & 2 & 0.28 & 2 \\
$\begin{array}{l}\text { Additive } \\
\text { manufacturing }\end{array}$ & 0.190117 & 3 & 0.47619 & 4 & 0.61 & 4 \\
\hline
\end{tabular}

regarding to the communication level with decision makers for required collection data. According to previous results, VIKOR and TOPSIS provided remarkable skill in the selection procedure than AHP. Figure 4 displays the agility in decision process of approaches.

6.2. Computational Complexity. The computation complexity for all suggested approaches was evaluated by considering the time complexity. Similar to [56], time complexity, $T$, was evaluated inside the calculations by considering the number of augmentations. In this study, logical operations and exponentiation were also used to measure the intricacy of time. Considering there are $c$ criteria and $p$ elective manufacturing processes, the AHP approach needs $c(c+1)+p(c+1)$ operations to find the AHP engineered degree for all choice grids, and finally, $p c$ operations are wanted to do the execution worldwide. In this way, the AHP time intricacy $\left(T_{\mathrm{AHP}}\right)$ is computed as follows:

$$
T_{\mathrm{AHP}}=c(c+1)+p(c+1)+p c .
$$

The TOPSIS technique requires $p c$ operations to compute NDM and $p c$ operations to compute the weighted decision matrix, and to compute the distances $d^{+}$, we need

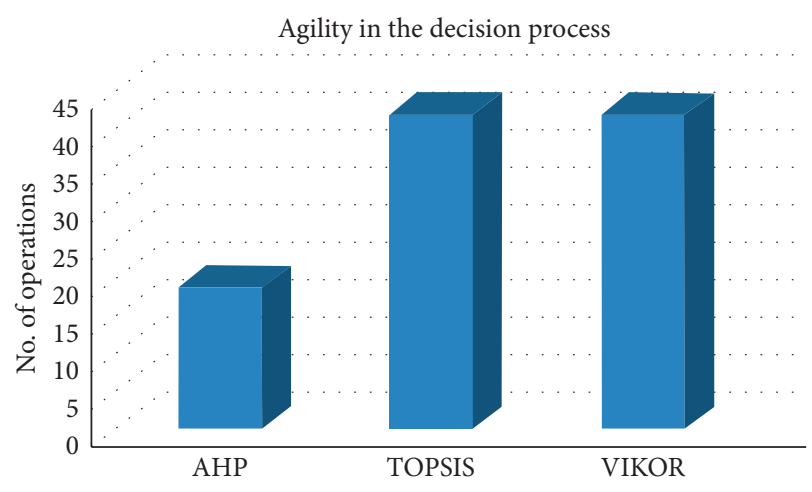

FIgURE 4: Agility in the decision process.

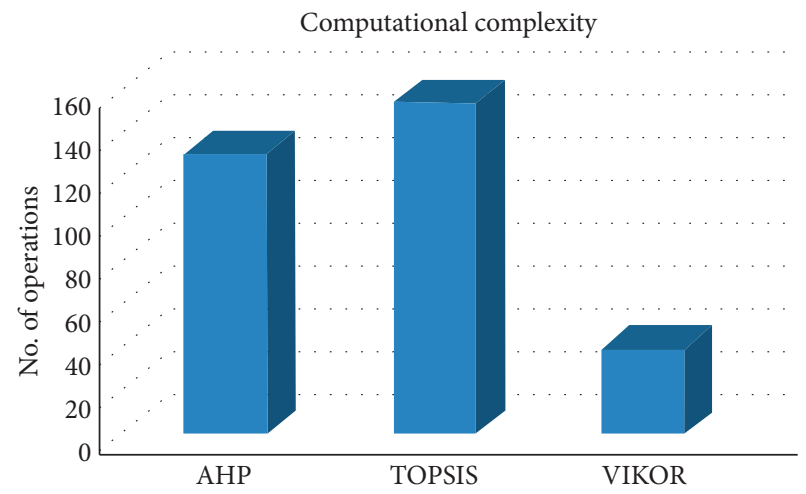

FIgURE 5: Computational complexity of approaches.

$p(c+1)$ operations, and to compute the distances $d^{-}$, we need $p(c+1)$ operations. Thus, the time intricacy $T_{\text {TOPSIs }}$ of TOPSIS technique is computed by the following equation:

$$
T_{\text {TOPSIS }}=p c+p c+p(c+1)+p(c+1)+p=4 p c+3 p .
$$

The VIKOR technique requires $2 \mathrm{~nm}$ operations to compute the best $f_{b}^{*}$ and worst $f_{b}^{-}$values decision matrix, $3 n$ operations to calculate the of $S, R$, and $Q$ decision matrix, and 4 operations to compute the $S^{-}, S^{*}, R^{-}$, and $R^{*}$. Therefore, the time complexity, $T_{\text {VIKOR }}$ of VIKOR approach is expressed through the following equation:

$$
T_{\text {VIKOR }}=3 c+3 p+4 \text {. }
$$

Considering the given case study, the TOPSIS technique required 155 operations, the AHP technique required 131 operations, and the VIKOR technique needed 40 operations. Consequently, it can be found that the VIKOR technique performed better than the TOPSIS and AHP techniques in terms of the complexity of computation, while TOPSIS performed better than AHP. Figure 5 shows the computational complexity of three approaches.

6.3. Number of Alternative Manufacturing Processes and Criteria. Regarding the number of criteria or alternatives, the AHP approach shows that it does force certain restrictions for determination procedure. In addition, TOPSIS 


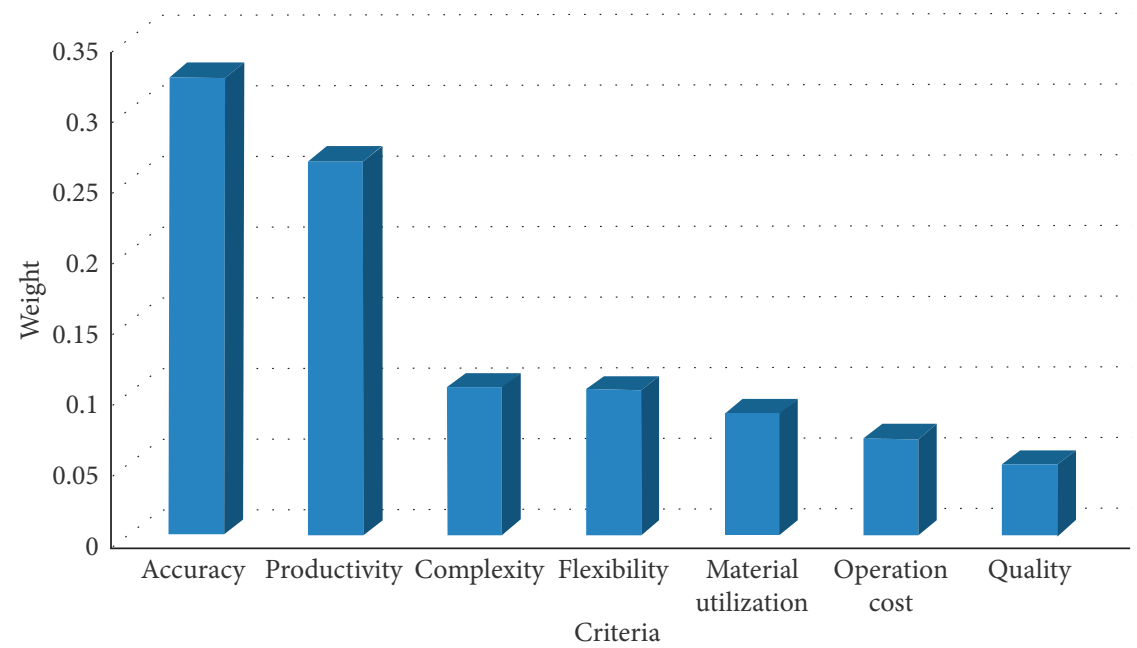

FIgURE 6: Importance of various criteria provided by AHP.

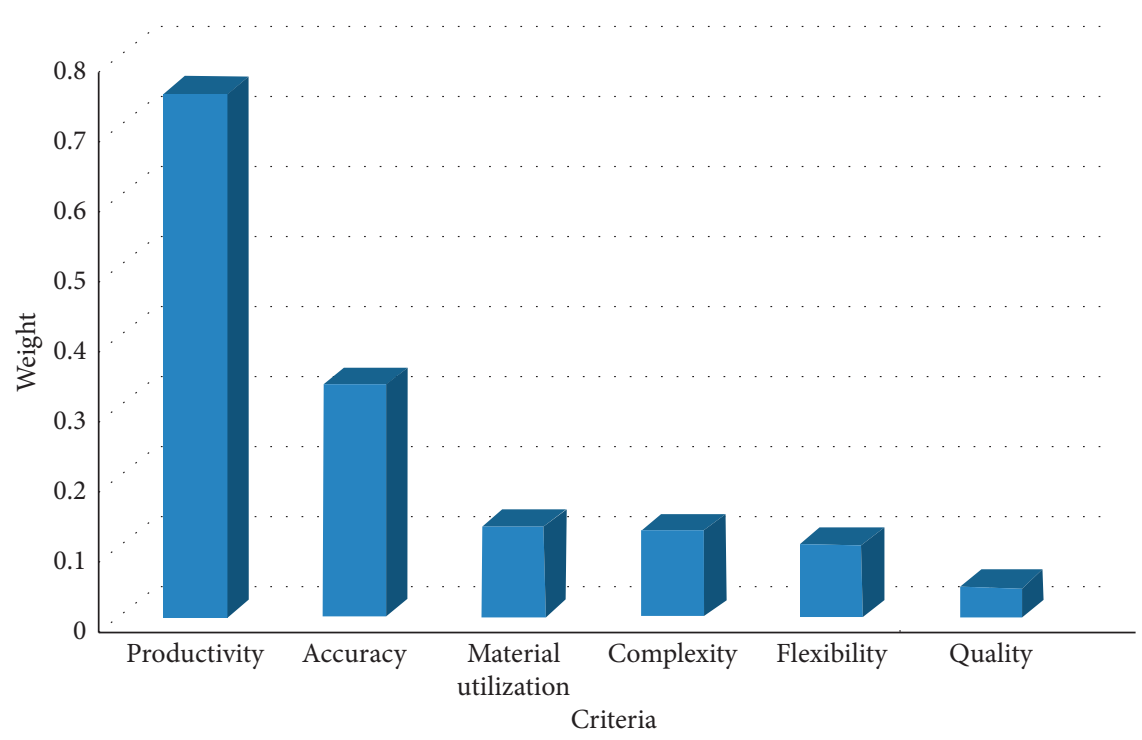

FIGURE 7: Importance order obtained after removal of criteria in AHP.

approach does not force restrictions for determination procedure. Saaty [48] suggested that the number of criteria or alternatives to be compared using AHP should be limited to nine so as to maintain a trade-off between human judgment and their consistency. In the applied case, using the seven main criteria and five choices, the utilization of the AHP methodology was impeccably feasible. Thus, the technique decision depends on the uniqueness of the existing conditions. For instance, while selecting another operation for another item, with many potential providers, superior decision can be done by using TOPSIS approach.

6.4. Adequacy in Supporting Group Decision-Making. Judgments can be allowed by approaches based on information acquired from more than one decision maker. For the VIKOR and TOPSIS approaches, acquisition of different judgments was performed using the following equations for the ratings of alternative manufacturing processes and weights of criteria:

$$
\begin{aligned}
& \widetilde{w}_{j}=\frac{1}{k}\left[\widetilde{w}_{j}^{1}+\widetilde{w}_{j}^{2}+\cdots+\widetilde{w}_{j}^{k}\right], \\
& \widetilde{w}_{i j}=\frac{1}{k}\left[\widetilde{x}_{j}^{1}+\widetilde{x}_{j}^{r}+\cdots+\widetilde{w}_{j}^{k}\right],
\end{aligned}
$$

where $k$ denotes the makers of decision.

In the case of AHP, in spite of the fact that this is not expressly considered in the approach developed in [56], the author suggests that an information acquisition should be done by using the mathematical mean of judgments. In order that the measure of information required by AHP approach is remarkable as compared to TOPSIS and VIKOR. The increase in the number of decision makers would bring about a larger growing in the AHP time unpredictability in comparison with TOPSIS and VIKOR 
TABLE 15: Comparative analysis of AHP, TOPSIS, and VIKOR.

\begin{tabular}{lccc}
\hline Parameters & AHP & TOPSIS & VIKOR \\
\hline Agility in the decision process & - & Better than AHP & Better than AHP and same with TOPSIS \\
Computational complexity & - & Better than AHP & Better than AHP and TOPSIS \\
Number of alternative manufacturing processes and criteria & - & Better than AHP & Better than AHP and same with TOPSIS \\
Adequacy in supporting group decision-making & - & Better than AHP & Better than AHP and same with TOPSIS \\
Addition or removal of criteria & - & Better than AHP & Better than AHP and same with TOPSIS \\
\hline
\end{tabular}

strategies. However, both approaches supported group decision-making and owing to the effect on the time intricacy, the VIKOR and TOPSIS approaches were identified to be the best.

6.5. Addition or Removal of a Criterion. In real situations, purchasing department or stakeholders might plan to add a new or remove an old criterion in order to assess the manufacturing processes. Hence, the importance of criteria order that obtained by selection approach must be convenient as well. Considering AHP approach with the seven criteria and respective weights, the importance of criteria order was accuracy $>$ productivity $>$ complexity $>$ flexibility $>$ material utilization $>$ operation cost $>$ quality. To assess the influence of removing an old criterion, an operation cost criterion is removed from the model. The results have indicated that there is a significant change in the importance order, and the new criteria importance order was accuracy $>$ productivity $>$ material utilization $>$ complexity $>$ flexibility $>$ quality. In the TOPSIS and VIKOR application cases, adding a new or removing an old criterion resulted in no variation at all to the criteria importance order. Figures 6 and 7 show criteria importance order before and after removing criterion. Finally, Table 15 illustrates an outline of these findings.

\section{Conclusions}

The decision regarding the choice of manufacturing process is a challenging issue in design and development of any product. It is also crucial for favorable outcomes as well as to meet the needs of cost reduction and better performance. In the literature, several different approaches have been proposed, including the AHP, TOPSIS, and VIKOR. However, until now, no any comparative studies of these approaches associated with the problems of manufacturing processes selection have been done. Henceforth, this paper has implemented a methodology to assess various approaches of MCDM. The valuation was done based on the following factors: computational complexity, agility during the decisionmaking process, number of alternative processes and criteria, adequacy in supporting a group decision, and addition or removal of a criterion. The methodology was implemented on a real case study. The criteria used to evaluate most suitable manufacturing process were identified as productivity, accuracy, complexity, flexibility, material utilization, quality, and operation cost. Five manufacturing processes were considered, which were sand casting, investment casting, gravity die casting, pressure die casting, and additive manufacturing. The results showed that each approach was suitable for the problems of manufacturing processes selection, in particular toward the support of group decision-making and uncertainty modelling. Moreover, the best manufacturing process that is obtained by proposed approaches was pressure die casting. In addition, in terms of computational complexity, VIKOR performed better than technique for order of preference by similarity to ideal solution (TOPSIS) and analytic hierarchy process (AHP). Furthermore, the TOPSIS and VIKOR approaches were better suitable to the problems of manufacturing process selection with regard to agility during the decision process, number of alternative processes and criteria, adequacy in supporting a group decision, and addition or removal of a criterion. The main advantages of the proposed approach are as follows: (1) it can be applied to a complex manufacturing process selection; (2) it has a simpler structure compared to the technique used; (3) it provides overall comparative analysis to assess different selection approaches; (4) it considers the following factors for comparative analysis: number of alternative processes and criteria, agility through the process of decisionmaking, computational complexity, adequacy in supporting a group decision, and addition or removal of a criterion. The main limitation of the proposed method is that the proposed model may undergo the multiple layers of criteria of manufacturing process selection; if a system has this issue, a proposed method requires to be improved. For the future work, the proposed work can be extended to include mathematical programming in the selection problem as well as fuzzy environment can be incorporated in MCDM approaches. Indeed, the multiple layers of criteria can also be utilized in the forthcoming work.

\section{Data Availability}

The data used to support the findings of this study are included within the article.

\section{Conflicts of Interest}

The authors declare that there are no conflicts of interest regarding the publication of this paper.

\section{Acknowledgments}

The authors extend their appreciation to the Deanship of Scientific Research at King Saud University for funding this work through research group no. RG-1439-56. 


\section{References}

[1] D. E. Whitney, "Manufacturing by design," Harvard Business Review, vol. 66, no. 4, pp. 83-91, 1988.

[2] D. G. Ullman, The Mechanical Design Process, McGraw-Hill, New York, NY, USA, 1992.

[3] Ž. Stević, D. Pamučar, A. Puška, and P. Chatterjee, "Sustainable supplier selection in healthcare industries using a new MCDM method: measurement of alternatives and ranking according to COmpromise solution (MARCOS)," Computers \& Industrial Engineering, vol. 140, Article ID 106231, 2020.

[4] A. Mardani, A. Jusoh, K. Nor, Z. Khalifah, N. Zakwan, and A. Valipour, "Multiple criteria decision-making techniques and their applications - a review of the literature from 2000 to 2014," Economic Research-Ekonomska Istraživanja, vol. 28, no. 1, pp. 516-571, 2015.

[5] G. Stojić, Ž. Stević, J. Antuchevičienè, D. Pamučar, and M. Vasiljević, "A novel rough WASPAS approach for supplier selection in a company manufacturing PVC carpentry products," Information, vol. 9, no. 5, p. 121, 2018.

[6] E. K. Zavadskas, Ž. Stević, I. Tanackov, and O. Prentkovskis, "A novel multicriteria approach-rough step-wise weight assessment ratio analysis method (R-SWARA) and its application in logistics," Studies in Informatics and Control, vol. 27, no. 1, pp. 97-106, 2018.

[7] S. Kumar, S. Kumar, and A. G. Barman, "Supplier selection using fuzzy TOPSIS multi criteria model for a small scale steel manufacturing unit," Procedia Computer Science, vol. 133, pp. 905-912, 2018.

[8] A. Memari, A. Dargi, M. R. Akbari Jokar, R. Ahmad, and A. R. Abdul Rahim, "Sustainable supplier selection: a multicriteria intuitionistic fuzzy TOPSIS method," Journal of Manufacturing Systems, vol. 50, pp. 9-24, 2019.

[9] C.-N. Wang, C.-Y. Yang, and H.-C. Cheng, "A fuzzy multicriteria decision-making (MCDM) model for sustainable supplier evaluation and selection based on triple bottom line approaches in the garment industry," Processes, vol. 7, no. 7, p. 400, 2019.

[10] F. R. L. Junior, L. Osiro, and L. C. R. Carpinetti, “A comparison between Fuzzy AHP and Fuzzy TOPSIS methods to supplier selection," Applied Soft Computing, vol. 21, pp. 194-209, 2014.

[11] X. Zhou and Z. Xu, "An integrated sustainable supplier selection approach based on hybrid information aggregation," Sustainability, vol. 10, no. 7, p. 2543, 2018.

[12] M. Alkahtani, A. Al-Ahmari, H. Kaid, and M. Sonboa, "Comparison and evaluation of multi-criteria supplier selection approaches: a case study," Advances in Mechanical Engineering, vol. 11, no. 2, 2019.

[13] M. A. Alias, S. Z. M. Hashim, and S. Samsudin, "Multi criteria decision making and its applications: a literature review," Jurnal Teknologi Maklumat, vol. 20, no. 2, pp. 129-152, 2008.

[14] A. Singh and S. K. Malik, "Major MCDM techniques and their application-A review," IOSR Journal of Engineering, vol. 4, no. 5, pp. 15-25, 2014.

[15] R. V. Rao, "Introduction to multiple attribute decisionmaking (MADM) methods," Decision Making in the Manufacturing Environment: Using Graph Theory and Fuzzy Multiple Attribute Decision Making Methods, pp. 27-41, Springer, London, UK, 2007.

[16] M. Aruldoss, T. M. Lakshmi, and V. P. Venkatesan, "A survey on multi criteria decision making methods and its applications," American Journal of Information Systems, vol. 1, no. 1, pp. 31-43, 2013.
[17] M. Erdoğan and İ. Kaya, "A systematic approach to evaluate risks and failures of public transport systems with a real case study for bus rapid system in Istanbul," Sustainable Cities and Society, vol. 53, Article ID 101951, 2020.

[18] P. Ishtiaq, S. A. Khan, and M.-u. Haq, "A multi-criteria decision-making approach to rank supplier selection criteria for hospital waste management: a case from Pakistan," Waste Management \& Research, vol. 36, no. 4, pp. 386-394, 2018.

[19] A. Alinezad, A. Seif, and N. Esfandiari, "Supplier evaluation and selection with QFD and FAHP in a pharmaceutical company," The International Journal of Advanced Manufacturing Technology, vol. 68, no. 1-4, pp. 355-364, 2013.

[20] I. Badi and M. Ballem, "Supplier selection using the rough BWM-MAIRCA model: a case study in pharmaceutical supplying in Libya," Decision Making: Applications in Management and Engineering, vol. 1, no. 2, pp. 16-33, 2018.

[21] G. Mehralian, A. R. Gatari, M. Morakabati, and H. Vatanpour, "Developing a suitable model for supplier selection based on supply chain risks: an empirical study from Iranian pharmaceutical companies," Iranian Journal of Pharmaceutical Research: IJPR, vol. 11, no. 1, p. 209, 2012.

[22] G. F. Stephen, A. Boluwaji, O. Olumide, and A. David, "Decision support model for supplier selection in healthcare service delivery using analytical hierarchy process and artificial neural network," African Journal of Business Management, vol. 10, no. 9, pp. 209-232, 2016.

[23] V. G. Venkatesh, R. Dubey, P. Joy, M. Thomas, V. Vijeesh, and A. Moosa, "Supplier selection in blood bags manufacturing industry using TOPSIS model," International Journal of Operational Research, vol. 24, no. 4, pp. 461-488, 2015.

[24] P. Manivel and R. Ranganathan, "An efficient supplier selection model for hospital pharmacy through fuzzy AHP and fuzzy TOPSIS," International Journal of Services and Operations Management, vol. 33, no. 4, pp. 468-493, 2019.

[25] A. Ahmadi, M. S. Pishvaee, and S. A. Torabi, "Procurement management in healthcare systems," Operations Research Applications in Health Care Management, Springer, Berlin, Germany, 2018.

[26] A. Forghani, S. J. Sadjadi, and B. F. Moghadam, "A supplier selection model in pharmaceutical supply chain using PCA," Z-TOPSIS and MILP: A Case Study, PLoS One, vol. 13, no. 8, Article ID e0201604, 2018.

[27] C. I. Enyinda, E. Dunu, and J. Bell-Hanyes, "A model for quantifying strategic supplier selection: evidence from a generic pharmaceutical firm supply chain," International Journal of Business, Marketing, and Decision Sciences, vol. 3, no. 2, pp. 23-44, 2010.

[28] P. Ghadimi and C. Heavey, "Sustainable supplier selection in medical device industry: toward sustainable manufacturing," Procedia CIRP, vol. 15, pp. 165-170, 2014.

[29] M. Bahadori, S. M. Hosseini, E. Teymourzadeh, R. Ravangard, M. Raadabadi, and K. Alimohammadzadeh, "A supplier selection model for hospitals using a combination of artificial neural network and fuzzy VIKOR," International Journal of Healthcare Management, pp. 1-9, 2017.

[30] N. Pourghahreman and A. R. Qhatari, "Supplier selection in an agent based pharmaceutical supply chain: an application of TOPSIS and PROMETHEE $\Pi$," Uncertain Supply Chain Management, vol. 3, no. 3, pp. 231-240, 2015.

[31] B. D. Rouyendegh and T. E. Saputro, "Supplier selection using integrated fuzzy TOPSIS and MCGP: a case study," ProcediaSocial and Behavioral Sciences, vol. 116, pp. 3957-3970, 2014.

[32] P. P. Dargie, K. Parmeshwar, and W. R. D. Wilson, "MAPS-1: computer-aided design system for preliminary material and 
manufacturing process selection," Journal of Mechanical Design, vol. 104, no. 1, pp. 126-136, 1982.

[33] C. Shea, P. Dewhurst, and C. Reynolds, "Computer-aided material and process selection," in Proceedings of the Fourth International Conference on Product Design for Manufacture and Assembly, vol. 1, pp. 399-414, Tokyo, Japan, 1989.

[34] K. Chan, C. King, and P. Wright, "COMPASS: computer oriented materials, processes, and apparatus selection system," Journal of Manufacturing Systems, vol. 17, no. 4, pp. 275-286, 1998.

[35] J. Farris and W. A. Knight, "Design for manufacture: expert processing sequence selection for early product design," CIRP Annals, vol. 41, no. 1, pp. 481-484, 1992.

[36] J.-C. Yu, S. Krizan, and K. Ishii, "Computer-aided design for manufacturing process selection," Journal of Intelligent Manufacturing, vol. 4, no. 3, pp. 199-208, 1993.

[37] A. M. K. Esawi and M. F. Ashby, "Cost estimates to guide preselection of processes," Materials \& Design, vol. 24, no. 8, pp. 605-616, 2003.

[38] R. E. Giachetti, "A decision support system for material and manufacturing process selection," Journal of Intelligent Manufacturing, vol. 9, no. 3, pp. 265-276, 1998.

[39] C. Smith, P. Wright, and C. Séquin, "The manufacturing advisory service: web-based process and material selection," International Journal of Computer Integrated Manufacturing, vol. 16, no. 6, pp. 373-381, 2003.

[40] G. Boothroyd, "Product design for manufacture and assembly," Computer-Aided Design, vol. 26, no. 7, pp. 505-520, 1994.

[41] F. H'mida, P. Martin, and F. Vernadat, "Cost estimation in mechanical production: the cost entity approach applied to integrated product engineering," International Journal of Production Economics, vol. 103, no. 1, pp. 17-35, 2006.

[42] T. Saric, G. Simunovic, K. Simunovic, and I. Svalina, "Estimation of machining time for CNC manufacturing using neural computing," International Journal of Simulation Modelling, vol. 15, no. 4, pp. 663-675, 2016.

[43] S. C. Feng and E. Y. Song, "A manufacturing process information model for design and process planning integration," Journal of Manufacturing Systems, vol. 22, no. 1, pp. 1-15, 2003.

[44] B. Denkena, M. Shpitalni, P. Kowalski, G. Molcho, and Y. Zipori, "Knowledge management in process planning," CIRP Annals, vol. 56, no. 1, pp. 175-180, 2007.

[45] J. F. Wang, W. L. Kang, J. L. Zhao, and K. Y. Chu, "A simulation approach to the process planning problem using a modified particle swarm optimization," Advances in Production Engineering \& Management, vol. 11, no. 2, pp. 77-92, 2016.

[46] H. B. Marri, A. Gunasekaran, and B. Kobu, "Implementation of computer-integrated manufacturing in small and medium enterprises," Industrial and Commercial Training, vol. 35, no. 4, pp. 151-157, 2003.

[47] M.-C. Lin, C.-C. Wang, M.-S. Chen, and C. A. Chang, "Using AHP and TOPSIS approaches in customer-driven product design process," Computers in Industry, vol. 59, no. 1, pp. 17-31, 2008.

[48] R. W. Saaty, "The analytic hierarchy process-what it is and how it is used," Mathematical Modelling, vol. 9, no. 3-5, pp. 161-176, 1987.

[49] A. Chauhan and R. Vaish, "Hard coating material selection using multi-criteria decision making," Materials \& Design, vol. 44, pp. 240-245, 2013.
[50] M. Behzadian, S. K. Otaghsara, M. Yazdani, and J. Ignatius, “A state-of the-art survey of TOPSIS applications," Expert Systems with Applications, vol. 39, no. 17, pp. 13051-13069, 2012.

[51] Y. Deng and F. T. S. Chan, "A new fuzzy dempster MCDM method and its application in supplier selection," Expert Systems with Applications, vol. 38, no. 8, pp. 9854-9861, 2011.

[52] G. Akman, "Evaluating suppliers to include green supplier development programs via fuzzy c-means and VIKOR methods," Computers \& Industrial Engineering, vol. 86, pp. 68-82, 2015.

[53] D. Kang and Y. Park, "Review-based measurement of customer satisfaction in mobile service: sentiment analysis and VIKOR approach," Expert Systems with Applications, vol. 41, no. 4, pp. 1041-1050, 2014.

[54] D. Lukic, M. Milosevic, A. Antic, S. Borojevic, and M. Ficko, "Multi-criteria selection of manufacturing processes in the conceptual process planning," Advances in Production Engineering \& Management, vol. 12, no. 2, pp. 151-162, 2017.

[55] A. M. A. Al-Ahmari, "Evaluation of CIM technologies in Saudi industries using AHP," The International Journal of Advanced Manufacturing Technology, vol. 34, no. 7-8, pp. 736-747, 2007.

[56] D.-Y. Chang, "Applications of the extent analysis method on fuzzy AHP," European Journal of Operational Research, vol. 95, no. 3, pp. 649-655, 1996. 